Moreira, TB, Leite, RCM, \& Moura, FNS. (2020). The contributions of the Pedagogical Residency to the Initial Training of Biological Sciences Teachers: the State of the Question. Research, Society and Development, 9(7): 1-22, e207974057.

\title{
Os contributos da Residência Pedagógica para a Formação Inicial de Professores de Ciências Biológicas: o Estado da Questão
}

The contributions of the Pedagogical Residency to the Initial Training of Biological

Sciences Teachers: the State of the Question

Las contribuciones de la Residencia Pedagógica a la Formación Inicial de Docentes de

Ciencias Biológicas: el Estado de la Cuestión

Recebido: 28/04/2020 | Revisado: 29/04/2020 | Aceito: 02/05/2020 | Publicado: 07/05/2020

Thaís Borges Moreira

ORCID: https://orcid.org/0000-0002-3064-2181

Universidade Federal do Ceará, Brasil

E-mail: thais.ufc@ @otmail.com

Raquel Crosara Maia Leite

ORCID: https://orcid.org/0000-0002-1563-9670

Universidade Federal do Ceará, Brasil

E-mail: raquelcrosara@ hotmail.com

Francisco Nunes de Sousa Moura

ORCID: https://orcid.org/0000-0002-8745-5010

Universidade Federal do Ceará, Brasil

E-mail: nunes.moura@alu.ufc.br

\section{Resumo}

Esta investigação incide na construção de um levantamento bibliográfico, do tipo Estado da Questão, para nortear uma proposta de dissertação sobre a formação de licenciandos de um curso de licenciatura em Ciências Biológicas inseridos no Programa Residência Pedagógica, sobretudo, com a temática sexualidade. Assim, este trabalho objetiva demonstrar como foi construído o Estado da Questão e como este possibilitou conhecer mais sobre pesquisas na área da Formação inicial com enfoque no Programa de Residência Pedagógica e Sexualidade. Para as buscas dos trabalhos foram utilizados: Portal de Periódicos da Coordenação de Aperfeiçoamento de Pessoal de Nível Superior (CAPES), a Biblioteca Digital Brasileira de 
Teses e Dissertações (BDTD) e os Anais do Encontro Nacional das Licenciaturas (ENALIC) de 2018. Os achados mostraram a diversidade de trabalhos voltadas as distintas contribuições da Residência Pedagógica nos cursos de licenciatura em Ciências Biológicas, bem como os aspectos teóricos-metodológicos adotados nas pesquisas. Todos estes resultados podem auxiliar em outras pesquisas similares a da temática em ênfase.

Palavras-chave: Educação; Sexualidade; Política Pública; Docência.

\begin{abstract}
This investigation focuses on the construction of a bibliographic survey, as State of the Question type, to guide a proposal for a dissertation on the training of undergraduate students in a Biological Sciences course included in the Pedagogical Residency Program, especially with the sexuality theme. Thus, this work aims to demonstrate how the State of the Question was built and how it made possible to learn more about research in the initial formation area with a focus on the Pedagogical Residency and Sexuality Program. To search for works were used: Portal of Journals of the Coordination for the Improvement of Higher Education Personnel (CAPES), the Brazilian Digital Library of Theses and Dissertations (BDTD) and the Proceedings of the 2018 National Meeting of Licentiate Programs (ENALIC). The results showed a diversity of works with different contributions of the Pedagogical Residency in undergraduate courses in Biological Sciences, as well as the theoretical and methodological aspects adopted in the research. All of these results can help with other research similar to the under emphasis in this work.
\end{abstract}

Keywords: Education; Sexuality; Public policy; Teaching.

\title{
Resumen
}

Esta investigación se centra en la construcción de una encuesta bibliográfica, del tipo Estado de la pregunta, para guiar una propuesta de disertación sobre la formación de estudiantes de pregrado en un curso de ciencias biológicas incluido en el Programa de residencia pedagógica, especialmente con el tema de la sexualidad. Por lo tanto, este trabajo tiene como objetivo demostrar cómo se construyó el Estado de la pregunta y cómo hizo posible aprender más sobre la investigación en el área de la formación inicial con un enfoque en el Programa de Residencia Pedagógica y Sexualidad. Para buscar los trabajos, se utilizaron los siguientes: Portal de Revistas de la Coordinación para el Mejoramiento del Personal de Educación Superior (CAPES), la Biblioteca Digital Brasileña de Tesis y Disertaciones (BDTD) y las Actas de la Reunión Nacional de Programas de Licencias 2018 (ENALIC). Los resultados 
mostraron la diversidad de trabajos dirigidos a las diferentes contribuciones de la Residencia Pedagógica en los cursos de pregrado en Ciencias Biológicas, así como los aspectos teóricos y metodológicos adoptados en la investigación. Todos estos resultados pueden ayudar en otra investigación similar a la del tema en énfasis.

Palabras clave: Educación; Sexualidad; Política pública; Docencia.

\section{Introdução}

Ao iniciar uma pesquisa, muitas vezes, vários de seus aspectos ainda estão indefinidos, nebulosos, sem uma delimitação precisa. Uma alternativa para sair destas indecisões e buscar trilhar um caminho é utilizar o Estado da Questão (EQ) como uma forma de pesquisar bibliografias sobre as temáticas selecionadas pelo pesquisador. Para Nóbrega-Therrien e Therrien (2004), o EQ configura então no esclarecimento da posição do pesquisador e de seu objeto de estudo na elaboração de um texto narrativo.

Ainda sobre os relatos de Nóbrega-Therrien e Therrien (2004), a finalidade deste tipo de pesquisa (EQ) é de levar o pesquisador a registrar, a partir de um rigoroso levantamento bibliográfico, como se encontra o tema ou o objeto de sua investigação no estado atual da ciência ao seu alcance. Assim, é possível situar melhor o pesquisador com o que existe de literatura sobre o tema, e desta maneira, possibilita clarear e delimitar a contribuição original do estudo no campo científico de seu trabalho. É possível fazer esta busca através de sites e periódicos, ou ainda, utilizando plataformas digitais que armazenam teses e dissertações. O pesquisador também pode utilizar trabalhos escritos para eventos locais, regionais, nacionais e internacionais.

Uma cautela para aqueles que trabalham com o EQ é entender como este funciona, sem confundir com o Estado da Arte e/ou a Revisão de Literatura. Para Nóbrega-Therrien e Therrien (2004), o EQ configura-se no clareamento da posição do pesquisador e de seu objeto de estudo na elaboração de um texto narrativo, na concepção de ciência e na sua contribuição epistêmica no campo do conhecimento. Já no Estado da Arte, o pesquisador terá um inventário descritivo da produção acadêmica e científica sobre o tema investigado, enquanto na Revisão de literatura este identificará o referencial de análise dos dados.

$\mathrm{O}$ objeto de estudo em análise faz parte dos anseios dos pesquisadores quanto ao desejo de uma formação integral de docentes das Ciências Biológicas, em âmbitos de saberes específicos e pedagógicos. Isso decorre em virtude dos cursos de licenciatura brasileiros priorizarem o ensino das disciplinas específicas, reduzindo a carga horária da necessária 
preparação didática dos licenciandos, como foi descrito por Gatti e Nunes (2009). Assim, torna-se necessária uma revolução nos cursos de licenciatura do Brasil, extinguindo as fragmentações formativas e propiciando diálogo entre todos os componentes curriculares necessários de preparação do professor em formação inicial, conforme Gatti (2010).

Seguindo a linha de raciocínio, os programas de complementação a formação docente contribuem na reversão desta fragmentada preparação acadêmica nas licenciaturas. Contudo, ressalta-se que estes não vêm substituir as formações nas universidades, mas complementar e preencher as lacunas das propostas de ensino.

Uma ressalva se faz no desejo inicial de inserir o tema Educação Sexual na dissertação, pesquisa mais ampla que a presente proposta investigativa. Este desejo acompanhou as preocupações de Moura e Leite (2019), ao identificarem as limitadas ofertas das proposituras desta temática em documentos governamentais brasileiros da educação básica, tais como os Parâmetros Curriculares Nacionais e a Base Nacional Comum Curricular. Porém, estas idealizações precisaram de ponderações após o EQ, no qual colaborou para a melhor delimitação das averiguações científicas.

Assim, todo este trabalho demonstra como foi construído o Estado da Questão e como este tem possibilitado um dos autores desta investigação a conhecer mais sobre pesquisas na área da formação inicial docente com o enfoque no Programa de Residência Pedagógica e, especificamente, na temática Sexualidade. Neste sentido, optamos por utilizar o Estado da Questão para auxiliar na composição de um projeto de dissertação a ser desenvolvido por uma universidade federal pública localizada no Nordeste brasileiro, uma vez que ainda não havia delimitado com clareza vários aspectos da proposta investigativa.

Como a partir do EQ, podemos ter uma visão mais ampla, optamos por escolher esta forma de pesquisa. As palavras-chave escolhidas foram todas relacionadas ao fato do que pretendia pesquisar durante o mestrado: o Programa de Residência Pedagógica da Biologia da Universidade Federal do Ceará e como a temática sexualidade está sendo executada dentro destes contextos formativos.

Com isso, o seguinte objetivo geral foi almejado: construir o EQ com base na formação inicial docente sobre as contribuições da residência pedagógica nos cursos de licenciatura em Ciências Biológicas. Os objetivos específicos incidiram: verificar as produções referentes a proposta de construção e identificar aspetos teóricos-metodológicos para uso na dissertação. Espera-se que tais contribuições reverberem também na reflexão da qualidade da formação docente nos cursos de licenciatura em Ciências Biológicas. 


\section{Contribuições do Estado da Questão - da procura}

A presente investigação se caracteriza como do tipo exploratória e descritiva, com abordagem qualitativa. Quanto ao procedimento para obtenção de dados, utilizou-se a pesquisa bibliográfica, que segundo Gil (2008, p. 50) possui a vantagem "de permitir ao investigador a cobertura de uma gama de fenômenos muito mais ampla do que aquela que poderia se pesquisar diretamente". Isso possibilita que o pesquisador analise as investigações relacionadas a sua temática de interesse em pesquisa com a literatura ao seu alcance.

Nesta investigação, escolhemos os seguintes descritores para a procura dos trabalhos nas plataformas: I - Formação de Professores (FP); II - Professores de Biologia (PB); III Residência Pedagógica (RP); e IV - Sexualidade (SD). Nas plataformas que permitiam buscas avançadas (combinação de descritores), utilizamos o operador booleano AND para melhor delimitação das investigações. Nos casos que não aceitavam tal combinação, estes foram aplicados de forma separada.

Posteriormente, determinamos as plataformas de busca dos dados. A primeira base de dados incidiu na Biblioteca Digital Brasileira de Teses de Dissertações (BDTD). A BDTD integra e dissemina, em um só portal de busca, os textos completos das teses e dissertações defendidas nas instituições brasileiras de ensino e pesquisa. O acesso a essa produção científica é livre de quaisquer custos. Assim, esta plataforma consegue dar maior visibilidade a pesquisas realizadas em programas de pós-graduação stricto sensu.

Em seguida, escolhemos o Portal de Periódicos da Coordenação de Aperfeiçoamento de Pessoal de Nível Superior (CAPES). Esta é uma biblioteca virtual que apresenta e disponibiliza a instituições de ensino e pesquisa no Brasil o melhor da produção científica internacional. Na plataforma ${ }^{1}$ existem mais de 45 mil títulos com texto completo, 130 bases de referências, 12 bases dedicadas exclusivamente a patentes, além de livros, enciclopédias e obras de referência, normas técnicas etc.

E por fim, escolhemos o VII Encontro Nacional das Licenciaturas (ENALIC) por trazer em seu escopo o I Seminário da Residência Pedagógica, contemplando diversas experiências realizadas ao longo do programa, entre elas, podendo vir a da temática em estudo; além de este ser o primeiro ano que os trabalhos foram publicados de maneira completa (em edições anteriores os trabalhos apresentavam apenas o resumo). O VII ENALIC, abrangendo também o VI Seminário Nacional do Programa Institucional de Bolsas 
de Iniciação à Docência (PIBID), trouxe um diálogo mais aberto entre professores formadores e da educação básica, licenciandos, pesquisadores, pós-graduandos e demais profissionais da educação.

A partir de um embasamento teórico e de investigações recentes e relevantes, foi promovida uma reflexão atual e contextualizada de questões implicadas à formação inicial de professores da educação básica. De acordo com a página do ENALIC ${ }^{2}$, o evento ocorreu pela primeira vez em 2010, e de lá para cá, já ocorreram sete edições que, assim como a última, sempre buscam trazer relações atuais dos desafios educacionais brasileiros.

Como recorte temporal, adotamos o intervalo entre 2014 a 2019. O ano de 2014 foi selecionado por ter se estabelecido o Plano Nacional de Educação (PNE). O PNE é um plano decenal, aprovado pela Lei ${ }^{\circ} 13.005 / 2014$, estando em vigor até 2024, e foi elaborado por força constitucional, o que significa que ultrapassa governos (Brasil, 2014). Assim, analisaremos os programas formativos, inclusive os voltados a Educação Sexual, nos cursos de licenciatura, desde 2014 até reformas educacionais de 2019.

As investigações se deram pela seguinte triagem, feita por Ribeiro (2018) e Moura e Leite (2020): Primeira Leitura (leitura de títulos); Segunda Leitura (triagem final de títulos); Terceira Leitura (leitura dos resumos e escolha das publicações); Quarta Leitura (Leitura total dos trabalhos); Seleção das publicações que irão compor o trabalho.

Realizada a triagem, obtivemos os trabalhos que correspondem a presente investigação. A tabela 1 expõe, resumidamente, toda a etapa de seleção, até chegada final das publicações dos achados que remetem a esta pesquisa nas plataformas de consulta.

\footnotetext{
${ }^{2}$ Disponível em:

<https://eventos.uece.br/siseventos/processaEvento/evento/exibeDetalhes.jsf;jsessionid=33B7744F02220DE477 3A0D9414216FE5.eventoss1 id=443\&area=detalhesEvento\&contexto=enalic $>$. Acesso em 08 ago. 2019>. Acesso em: 08 de agosto de 2019.
} 
Tabela 1 - Quantificação dos trabalhos encontrados nas plataformas investigadas.

\begin{tabular}{|c|c|c|}
\hline Descritores & BDTD & CAPES \\
\hline FP AND EB & 7 & 314 \\
\hline FP AND RP & 17 & 61 \\
\hline FP AND SD & 165 & 159 \\
\hline RP AND EB & 3 & 17 \\
\hline RP AND SD & 2 & 13 \\
\hline Total de trabalhos encontrados & 194 & 564 \\
\hline Trabalhos escolhidos após a leitura dos títulos & 29 & 30 \\
\hline Trabalhos selecionados para leitura completa & 11 & 24 \\
\hline Trabalhos selecionados para a pesquisa & 8 & 8 \\
\hline \multicolumn{3}{|c|}{$\begin{array}{l}\text { Anais do ENALIC } \\
\end{array}$} \\
\hline Descritores & \multicolumn{2}{|c|}{2018} \\
\hline $\mathrm{FP}$ & \multicolumn{2}{|c|}{21} \\
\hline EB & \multicolumn{2}{|c|}{9} \\
\hline RP & \multicolumn{2}{|c|}{28} \\
\hline $\mathrm{SD}$ & \multicolumn{2}{|c|}{1} \\
\hline Total de trabalhos encontrados & \multicolumn{2}{|c|}{59} \\
\hline Trabalhos escolhidos após a leitura dos títulos & \multicolumn{2}{|c|}{39} \\
\hline Trabalhos selecionados para leitura completa & \multicolumn{2}{|c|}{21} \\
\hline Trabalhos selecionados para a pesquisa & \multicolumn{2}{|c|}{7} \\
\hline
\end{tabular}

Fonte: Elaborada pelos autores.

A redução no número de trabalhos, etapa após etapa, ocorreu devido a muitos deles não terem nenhuma relação com o objeto de estudo. Muitos trabalhos relacionados à formação de professores, por exemplo, lidavam com experiências de professores que já estão em sala de aula, e não em início de formação (como é o que procurávamos), ou ainda, tratavam de outros cursos, como por exemplo, educação física.

Para o descritor "Residência Pedagógica" outras áreas foram encontradas, como as residências na área da saúde. Em sexualidade, muitos trabalhos também traziam a temática de uma maneira mais morfofisiológica que, apesar de ser importante, também foge do que procuramos. Feita a triagem, adquirimos os trabalhos já publicados voltados a nossa temática. A partir destes achados, realizamos, no próximo subtópico, uma análise teórica-metodológica nas investigações, destacando tais discussões no meio científico.

Finalmente, após a longa triagem, nos debruçamos sob a leitura dos trabalhos encontrados, e assim, clarear mais o caminho sobre o objeto de estudo com base nas leituras dos 65 trabalhos encontrados. Ao analisar os achados, observamos que alguns trabalhos não seriam utilizados, pois estes não contribuiriam na organizar de pesquisas com similaridades ao proposto. Ainda foram excluídas pesquisas que fugiram do que buscávamos (mesmo após várias etapas, alguns trabalhos, por exemplo, de formação continuada que nem estavam 
(CC BY 4.0) | ISSN 2525-3409 | DOI: http://dx.doi.org/10.33448/rsd-v9i7.4057

relacionadas ao PRP, estavam presentes, e por isso, os removemos). Desta forma, para compor esta parte da pesquisa, utilizamos 23 trabalhos. As descrições destes achados, em análise teórica-metodológica, se encontram na próxima subseção.

\section{Contribuições do Estado da Questão - dos achados}

Os arquivos encontrados no Estado da Questão, como esperados, fazem relação com a presente pesquisa. Estes foram organizados e inseridos no Quadro 1 a seguir, acompanhados de proposições teóricas-metodológica, como norteado por Nóbrega-Therrien e Therrien (2004).

Quadro 1- Trabalhos identificados no Estado da Questão.

\begin{tabular}{|c|c|c|c|}
\hline $\mathbf{N}^{\circ}$ & TÍTULO & $\begin{array}{l}\text { TIPO DE } \\
\text { TRABALHO }\end{array}$ & $\begin{array}{l}\operatorname{AUTOR}(\mathbf{E S}) \\
\text { ANO }\end{array}$ \\
\hline \multicolumn{4}{|c|}{ BDTD } \\
\hline 1 & $\begin{array}{l}\text { Educação sexual e a formação de } \\
\text { professores: uma proposta para a } \\
\text { formação inicial dos licenciandos em } \\
\text { Ciências Naturais (FUP) }\end{array}$ & Dissertação & Abreu, 2017 \\
\hline 2 & $\begin{array}{l}\text { A inserção profissional do egresso do } \\
\text { Programa Residência Pedagógica da } \\
\text { Universidade Federal de São Paulo } \\
\text { (UNIFESP) }\end{array}$ & Dissertação & Conceição, 2018 \\
\hline 3 & $\begin{array}{l}\text { Estudos sobre o programa da residência } \\
\text { pedagógica da UNIFESP: uma } \\
\text { aproximação entre a universidade e } \\
\text { escola na formação de professores }\end{array}$ & Dissertação & Poladian, 2014 \\
\hline 4 & $\begin{array}{l}\text { Programa Residência Pedagógica - } \\
\text { UNIFESP: um estudo da inserção } \\
\text { profissional à docência }\end{array}$ & Dissertação & Barbedo, 2018 \\
\hline 5 & $\begin{array}{l}\text { As contribuições do currículo da } \\
\text { formação para a prática pedagógica } \\
\text { docente com gênero e sexualidade na } \\
\text { educação básica }\end{array}$ & Tese & Santos, 2016 \\
\hline 6 & $\begin{array}{l}\text { Relações de gênero, interseccionalidades } \\
\text { e formação docente }\end{array}$ & Dissertação & Vasconcelos, 2018 \\
\hline 7 & $\begin{array}{l}\text { Sexualidade: uma proposta metodológica } \\
\text { para formação inicial de professores de }\end{array}$ & Dissertação & Oliveira, 2018 \\
\hline
\end{tabular}




\begin{tabular}{|c|c|c|c|}
\hline & Ciências Naturais & & \\
\hline 8 & $\begin{array}{l}\text { Formação inicial docente para a } \\
\text { educação sexual: revelando realidades de } \\
\text { licenciaturas em ciências biológicas }\end{array}$ & Dissertação & Oliveira, 2016 \\
\hline \multicolumn{4}{|c|}{ CAPES } \\
\hline 1 & $\begin{array}{l}\text { Sexo e sexualidade: tabu, polêmica ou } \\
\text { conceitos polissêmicos? Reflexões } \\
\text { sobre/para a formação de educadores }\end{array}$ & Artigo & $\begin{array}{l}\text { Martines \& Rossarolla, } \\
2018\end{array}$ \\
\hline 2 & $\begin{array}{l}\text { Relatando e refletindo sobre as } \\
\text { experiências do PIBID Biologia (IF } \\
\text { Goiano - Câmpus Urutaí) no período de } \\
2011 \text { a } 2013\end{array}$ & Artigo & Gonçalves et al., 2014 \\
\hline 3 & $\begin{array}{l}\text { Formação inicial docente e suas relações } \\
\text { dentro do âmbito escolar }\end{array}$ & Artigo & Cunha et al., 2016 \\
\hline 4 & $\begin{array}{l}\text { O PIBID e a inserção à docência: } \\
\text { experiências, possibilidades e dilemas }\end{array}$ & Artigo & Paniago et al., 2018 \\
\hline 5 & $\begin{array}{l}\text { Profissionalização docente: construindo } \\
\text { saberes a partir da prática no PIBID }\end{array}$ & Artigo & Morais \& Ferreira, 2014 \\
\hline 6 & $\begin{array}{l}\text { Estágio de docência em biologia: relatos } \\
\text { de experiências e constituição de } \\
\text { identidades docentes }\end{array}$ & Artigo & Maciel \& Rosa, 2016 \\
\hline 7 & $\begin{array}{l}\text { A formação docente e o PIBID - } \\
\text {--subprojeto de Biologia do IFRN/ } \\
\text { Macau: uma interlocução entre a } \\
\text { formação inicial e continuada }\end{array}$ & Artigo & Lima \& Ferreira, 2018 \\
\hline 8 & $\begin{array}{l}\text { Comunidade de aprendizagem da } \\
\text { docência em estágio curricular } \\
\text { obrigatório: aprendizagens evidenciadas } \\
\text { pelos licenciandos }\end{array}$ & Artigo & Guerta \& Camargo, 2015 \\
\hline \multicolumn{4}{|c|}{ ENALIC } \\
\hline 1 & $\begin{array}{l}\text { Formação de professores na articulação } \\
\text { escola/universidade: intenção e resultado } \\
\text { parcial do Programa de Residência } \\
\text { Pedagógica na UFT }\end{array}$ & Artigo & Santos et al., 2018 \\
\hline 2 & $\begin{array}{l}\text { A multidisciplinaridade no PIBID e no } \\
\text { PRP: novo desafio na formação docente }\end{array}$ & Artigo & Lopes et al., 2018 \\
\hline 3 & $\begin{array}{l}\text { Modelos inovadores no campo da } \\
\text { formação docente inicial: } \text { um estudo }\end{array}$ & Artigo & Pinheiro et al., 2018 \\
\hline
\end{tabular}


(CC BY 4.0) | ISSN 2525-3409 | DOI: http://dx.doi.org/10.33448/rsd-v9i7.4057

\begin{tabular}{|l|l|l|l|}
\hline $\mathbf{4}$ & $\begin{array}{l}\text { analítico da implementação do PIBID e } \\
\text { da Residência Pedagógica no IFTM }\end{array}$ & $\begin{array}{l}\text { Lobilizações do programa residência } \\
\text { pedagógica na universidade de } \\
\text { Pernambuco campus Mata Norte } 2018\end{array}$ \\
\hline $\mathbf{5}$ & $\begin{array}{l}\text { Residência Pedagógica e seus impactos } \\
\text { nas escolas-campo da educação básica e } \\
\text { nas licenciaturas }\end{array}$ & $\begin{array}{l}\text { Artigo } \\
\text { Bolsa de Iniciação à Docência (PIBID) } \\
\text { na escola alvorada: as expectativas frente } \\
\text { às ações do Programa Residência } \\
\text { Pedagógica (RP) }\end{array}$ & Artigo \\
\hline $\mathbf{7}$ & $\begin{array}{l}\text { O legado do Programa Institucional de } \text { et al., } 2018 \\
\text { como encontro entre a formação inicial e } \\
\text { contínua de professores }\end{array}$ & Artigo & Craveiro et al., 2018 \\
\hline
\end{tabular}

Fonte: Elaborado pelos autores.

As primeiras observações consistiram nos teóricos utilizados nas pesquisas, vistos durante o referencial dos trabalhos. Com relação a estes achados, observou-se que alguns autores sempre estavam presentes quando o tema do trabalho era voltado para a sexualidade, como por exemplo: Guacira Lopes Louro e Michel Foucalt. No trabalho de Lima e Ferreira (2018) se destacaram outros autores, além dos citados acima, das áreas de currículo e formação de professores.

Sendo assim, chegou-se a conclusão que o perfil desta pesquisa segue um caráter qualitativo, e para alcançar o intento do estudo foi utilizada a entrevista semiestruturada, já que esta tornou-se um instrumento de coleta de dados eficiente frente a necessidade de captar as percepções dos participantes, diante da problemática estudada. Como fundamentação teórica da pesquisa foram utilizados estudos de autores que discutem sobre a formação docente, entre eles: Freire (1996), Pimenta (2008), Farias (2009) e Cunha (2014) (Lima \& Ferreira, 2018, p. 318).

Os trabalhos apresentavam certa similaridade quanto à metodologia, sobretudo na abordagem de caráter qualitativo, caracterizados em todos os trabalhos lidos. Em um dos achados relatou que nesta metodologia: 
O investigador qualitativo não inicia sua pesquisa já sabendo onde irá chegar, mas vai construindo sua pesquisa à medida que recolhe informações. 5. Importância do significado: Na pesquisa qualitativa, existe preocupação em considerar o significado que os participantes atribuem ao problema de pesquisa (Abreu, 2017).

Existiram autores que antes de iniciarem as suas investigações, também se utilizaram de pesquisas similares a esta, do Estado da Questão, como o utilizado por Barbedo (2018), que almejou observar o que está se publicando sobre a Residência Pedagógica. As minhas buscas vão ao encontro dos resultados da autora: existe um grande número de trabalhos relacionados à "residência", porém, poucos são vinculados à docência, sendo a sua grande maioria presente na área da saúde e não da educação.

A maioria dos trabalhos se utilizou de grupo focal, entrevistas - como em Oliveira (2016), que utilizou entrevistas semiestruturas e até estudo de caso para compor os seus trabalhos. Os que utilizaram questionários fizeram de maneira semiestruturada. Na pesquisa de Lima e Ferreira (2018), estes utilizaram entrevista semiestrutura para os seus resultados. Pinheiro, Gaspar e Ribeiro (2018) também utilizaram de grupo focal e posteriormente, um questionário, para avaliar as contribuições do PRP para a formação inicial - no trabalho apresentado existem apenas os primeiros resultados desta pesquisa e as futuras metodologias que esse autor fez, e por isso, enfatizamos que ainda será feita esta parte da pesquisa.

Na dissertação de Conceição (2018), esta investigou quais as contribuições trazidas do PRP para os egressos em relação à superação das dificuldades iniciais da vida docente. Apesar de não ser o foco da proposta de dissertação que deu origem a esta pesquisa (egressos na prática docente), o trabalho de Conceição foi bem interessante e permaneceu no EQ por ela trazer algo relevante: a partir de um perfil que ela pode selecionar uma professora que foi seu estudo de caso.

Martines e Rossarolla (2018) fizeram o registro dos encontros, dos diálogos e de muitas reflexões de sua pesquisa por meio de escrita de planejamentos dos encontros e a gravação em vídeos das interações com os colaboradores da pesquisa, os educadores selecionados. Um questionário foi utilizado nesta pesquisa, para montar um perfil dos colaboradores da investigação, porém, até as falas ditas durante as respostas ao questionário foram observadas e transcritas no trabalho. Analisando as respostas foi possível perceber a dificuldade que os futuros professores tinham em abordar o tema sexualidade, por exemplo:

Estes diálogos mostram que eles já refletiam quanto à sua formação enquanto educadores sexuais, com alguns evidenciando que não se sentiam ainda preparados para discussões sobre o assunto, pois enquanto preenchiam as respostas surgiam 
comentários como: - "Nossa, mas eu sabia isso e agora esqueci"; - "Eu já vi alguma coisa sobre isso, mas agora não lembro"; - "Difícil isso, hein?" (Martines \& Rossarolla, 2018, p. 280).

O estudo de análise documental foi encontrado em muitos trabalhos, incluindo o de Poladian (2014), no qual foi analisado o Projeto Político Pedagógico do curso de Pedagogia da Universidade Federal de São Paulo (UNIFESP) e como o Programa Residência Pedagógica estaria na conformidade da proposta de formação do curso e o que propõe a Residência. Na pesquisa de Maciel e Rosa (2016), houve a análise de relatórios dos estágios, onde ocorreu a partir da desmontagem dos textos em fragmentos, unificando aqueles discursos que se repetiram a fim de classificá-los e interpretá-los.

Outras pesquisas similares ao que se deseja pesquisar na proposta de dissertação trazem outros questionamentos, além dos voltados para as práticas relacionadas à sexualidade. Santos (2016) falam sobre a importância da reflexão dentro das práticas docentes, principalmente dentro da formação inicial, eles mostram também que a reflexão sobre a prática docente e sobre as relações que permeiam o ambiente escolar permitem uma análise aprofundada do que é ser professor.

No trabalho de Abreu (2017) e Oliveira (2018), ambas as autoras criaram uma disciplina com foco na sexualidade para alunos que estavam cursando Licenciatura em Ciências Naturais da Faculdade UnB Planaltina, onde ao longo dos módulos iam-se discutindo como os futuros docentes enfrentariam a sala de aula. Vasconcelos (2018) criou Encontros Formativos para tratar com alunos a temática sexualidade, porém esta autora foi para as escolas, ao invés de trabalhar com os futuros docentes.

O trabalho de Santos (2016) mostra que ainda se faz necessária mais pesquisas sobre a educação em cursos de licenciatura, especificamente nos programas de complementação a formação docente, pois há lacunas nos programas curriculares nos cursos de Graduação e Pósgraduação, com ausência de disciplinas que estudem gênero, não tendo assim, muitas disciplinas do currículo básico com esse foco.

Algo interessante e que nos fez refletir sobre a importância desta investigação, foram os trabalhos que citam o PIBID e a Residência como momentos únicos na formação inicial. Isso mostra como precisamos de tais momentos para que os licenciandos saiam de maneira mais preparada para a carreira docente. Ao passo que muitos dizem ainda não se sentirem amparados pela formação docente através de disciplinas, são nestes programas que estes têm a melhor oportunidade de preencher essa lacuna. 
Assim, com a compreensão de que a formação não suporta todo o processo de aprendizagem da docência, espera-se que os futuros professores obtenham mais que um título; vislumbra-se uma formação que permita aos licenciandos experimentarem situações de aprendizagem de modo a desenvolverem a capacidade de mobilizarem, em sua futura prática, os vários saberes necessários ao exercício da docência profissional, pois as tramas que ocorrem na atual sociedade contemporânea, marcada por inúmeros avanços e complexidade, tornam o exercício da docência uma atividade cada vez mais intrincada e ambígua, o que requer dinamismo e atualização constante dos saberes necessário ao seu exercício (Paniago, Sarmento, \& Rocha, 2018, p. 5-6).

Para Morais e Ferreira (2014), a partir do momento em que os bolsistas (no caso do trabalho, bolsistas PIBID) são inseridos na escola, estes vão além de adquirir os conhecimentos teóricos nas Universidades e nos Institutos Superior de Educação, estes estão também ganhando os mais variados saberes com intuito de assegurar a sua prática profissional.

Essa relação entre o PRP e o PIBID está presente nos trabalhos lidos. Lopes, Joaquim e Souza (2018) trazem um pouco dessa relação por falarem do surgimento de ambos e como eles têm objetivos até similares.

Tanto o PIBID quanto o PRP visam contribuir na formação de professores, uma vez que promovem uma parceria entre IES e escolas de educação básica da rede pública de ensino, inserindo de forma ativa os licenciandos na realidade escolar propiciando, desta forma, a construção de conhecimentos obtidos por meio da vivência. Em 2018, além do Edital para o PIBID foi lançado o Edital para o PRP oferecendo a possibilidade às Universidades Comunitárias de participarem com a inscrição dos subprojetos multidisciplinares (Lopes, Joaquim, \& Souza, 2018, p. 3).

Tratando-se de Residência Pedagógica em si, estávamos receosos sobre como buscar o Referencial Teórico de algo tão novo. Porém, graças a participação em um congresso ligado à licenciatura, sabíamos exatamente onde encontrar trabalhos sobre tal programa. Recorremos então aos anais do ENALIC, evento que possibilitou o primeiro encontro dos Residentes, juntamente com os trabalhos dos "pibidianos" em um mesmo evento.

Muitos trabalhos da Residência abordavam também os estágios, sua importância e como o PRP se integrava nessa parte da formação dos docentes. A integração entre estágios e PRP é explicitada no trabalho Lira et al. (2018), onde mostra que o PRP já havia entre muitos objetivos, o de aperfeiçoar o estágio, como diz a citação abaixo:

Integrado a Política Nacional de Formação de Professores, o Programa de Residência Pedagógica é uma das ações da Capes e tem como objetivo proporcionar o aperfeiçoamento do estágio curricular supervisionado nos cursos de licenciatura de 
todo o Brasil, promovendo a imersão desses graduandos em escolas públicas de educação básica (Lira et al., 2018, p. 3).

Acho fundamental também estabelecer as diferenças entre o que é o PRP e o que seriam os estágios. No trabalho de Santos, Santos e Alves (2018), já percebi certas distinções de ambos, como expresso nesse pequeno parágrafo citado abaixo:

Porém, em que o programa de residência pedagógica se diferencia do estágio curricular obrigatório? Em vários quesitos: a forma de ingresso, tempo de atuação, entre outros. É possível visualizar essa diferença, pois no programa de residência pedagógica os alunos-residentes, decidiram participar, se inscreveram no processo seletivo e após serem aprovados, participaram de um curso de formação com debates, mesa redondas, leituras de textos relacionados a prática educativa, aprendizagem significativa com as professoras preceptoras e professores orientadores - atividades não realizadas no estágio curricular obrigatório e depois irem à escola (Santos, Santos \& Alves, 2018, p. 7).

Para Costa et al. (2018), os objetivos da residência vão desde a articulação e aperfeiçoamento da formação dos futuros professores, a avaliação das práticas pedagógicas vividas nas licenciaturas, o fortalecimento da relação entre as escolas e a universidades até a apropriação crítica da Base Nacional Comum Curricular (BNCC). Isso é consolidado pela importância do programa para propiciar experiências formativas em diversos contextos profissionais atrelados à docência, como os vivenciados por Silva, Dantas e Viana (2020), Rosa e Goi (2020), entre outros.

Ainda para Costa et al. (2018), o processo reflexivo é compreendido como um processo formativo privilegiado que colabora para o desenvolvimento dos indivíduos e dos coletivos institucionais, fortalecendo a autonomia dos mesmos na definição dos seus modos de caminhar em relação aos compromissos políticos e pedagógicos com a comunidade. Assim, os estágios e, agora a residência, entrariam nesta etapa de reflexão, para além do "fazer", o aluno tem essa oportunidade de não somente estar presente na escola, mas também poder refletir sobre o que está aprendendo e ensinando ali.

Na pesquisa de Magalhães et al. (2018) foram apresentados alguns aspectos sobre o PRP da Universidade Iguaçu que, em seu impacto social, conseguiu demonstrar que o programa se destaca na formação/capacitação de profissionais e na prestação de serviços à população, e assim, acaba por aperfeiçoar a formação prática dos futuros docentes junto às políticas públicas, corroborando positivamente para o que se tornou o PRP. 
Porém, o próprio programa e sua vinculação a princípio geraram dúvidas e incertezas, visto que o cenário político atual não favorece políticas educacionais. Na pesquisa de Craveiro et al. (2018), este mostra essa incerteza se, de fato, o programa seria algo positivo para formação inicial dos futuros professores.

O RP é um programa novo, lançado em meio a uma conjuntura de crise política no país, em que o Congresso Nacional aprova Emenda Constitucional, EC 95/16, que praticamente congela os investimentos públicos em vários setores, dentre eles a educação, logo, o Residência Pedagógica recebeu críticas de várias entidades da área da educação. Uma das preocupações era que o programa tivesse o seu objetivo desviado para o uso dos licenciandos como mão de obra barata nas escolas, assim como, uma prática deslocada da reflexão teórica-crítica, assumindo outra identidade (Craveiro et al., 2018, p. 2).

Como dito acima, o sucesso do programa, na sua busca de aperfeiçoar o estágio, e trazer a reflexão e pensamento crítico para a formação docente, fizeram do programa o sucesso atual, tal "sucesso" é percebido a cada leitura dos artigos, que mostram que os residentes estão lidando da melhor maneira possível com o programa, desenvolvendo projetos, articulações com a escola/comunidade.

Selecionamos também trabalhos relacionados ao Estágio Supervisionado. Tal escolha se deu pelo fato de ver a importância dos estágios para a formação inicial (de uma maneira diferente ao do PIBID). Acredito que estas pesquisas relacionadas ao estágio também me ajudem a montar meu referencial teórico.

A pesquisa de Guerta e Camargo (2015) foi realizada com cinco alunos graduandos de uma turma composta por vinte e um alunos do curso de Ciências Biológicas - Licenciatura Plena, da Universidade Federal de São Carlos (UFSCar), campus de São Carlos, durante o período de dois anos em que estavam realizando o estágio curricular obrigatório em escolas públicas de Ensino Fundamental e Médio.

Trabalhos que envolviam o PIBID também foram selecionados para a leitura completa, visto que pela experiência pessoal dos autores (dois foram bolsistas do PIBID e um foi coordenador), este foi um programa essencial na formação inicial docente. Um dos trabalhos que falou do PIBID foi o de Gonçalves et al. (2014). Nesta pesquisa, os relatos das atividades desenvolvidas pelo PIBID Biologia do IF Goiano - Câmpus Urutaí foram mantidos em arquivo pelo grupo, e analisados. Assim, eles relataram e refletiram sobre as principais ações/atividades desenvolvidas entre o segundo semestre de 2011 e o primeiro semestre de 2013. 
Nota-se, ao longo dos achados, diversas contribuições das propostas de complementação à formação docente (Estágio, PIBID e Residência Pedagógica) como contribuintes significativos da formação inicial, tendo suporte pedagógico agregado ao cientifico, os quais, muitas vezes, estão distantes nas disciplinas curriculares. Um destes saberes incidem no ensino de sexualidade, tão necessário para formação humana e docente, mas distante da preparação acadêmica nos cursos de licenciatura.

\section{Contribuições do Estado da Questão - Algumas Considerações}

Ao longo das leituras, observamos cada metodologia com muita cautela, o que contribuiu na construção do percurso metodológico da proposta de dissertação a ser elaborada e auxiliará demais produções similares a tal proposição. Houve também importantes delimitações para a pesquisa, como exemplo a necessidade de se montar um perfil dos residentes por intermédio de questionário (como o semestre que cursam e se já tiveram outras experiências fora do PRP, por exemplo), como feito por Conceição (2018).

Além disso, ainda não estava definido se seria trabalhado apenas com os residentes ou se seria desenvolvido alguma pesquisa também com os alunos das escolas. O público-alvo dos trabalhos selecionados sempre estava voltado para os egressos do programa Residência ou para os próprios residentes. No início, acreditava-se que trabalhar com os alunos da escola era uma boa opção, porém, após ler os trabalhos cujo foco era formação de professores, de fato, pareceu-nos agora mais efetivo a escolha de trabalhar na Universidade dentro do Programa Residência Pedagógica com os residentes. Esperamos ainda que após o questionário teremos uma melhor visão sobre como trabalhar com eles, o conhecido professor iniciante nos trabalhos (Borbedo, 2018).

Santos (2016) falou sobre sexualidade, mas não ficou apenas nesse aspecto. Com isso, pretendo trazer dentro da pesquisa da Dissertação, momentos de reflexão destes residentes sobre suas práticas. Como a proposta investigativa na dissertação é sobre a residência e a sua importância para a formação inicial, acredito que possa encaixar outras perguntas ligadas a formação inicial que não sejam apenas ligadas a sexualidade.

Como dito acima, Vasconcelos (2018) criou encontros formativos que, adequando para a pesquisa de dissertação, podemos trazer tais encontros para os Residentes. Assim, após o questionário e os encontros em grupo focal, será possível a criação de encontros formativos que pretendem preencher as lacunas percebidas na análise. 
Algo que também desejamos trazer para o trabalho, caso encontre isso nos residentes da UFC, e que encontramos nas leituras, foi o fato de ressaltar-se a importância do PRP, visto que seu impacto é positivo nas ações docentes. Em tempos de cortes de verbas orçamentárias, trabalhos como esta pesquisa são de fundamental importância para mostrar a relevância de se investir em formação de professores, principalmente em formação inicial, visto que é na Universidade que se formam os pilares para a formação desse futuro professor. Um exemplo, foi o trabalho de Magalhães et al. (2018) que nas falas dos residentes os autores perceberam exatamente o que eu estou transmitindo.

Outro ponto que salta nas falas dos residentes é o destaque que atribuem à universidade pela adesão ao programa. Nesse sentido, ressaltamos a importância da atuação de uma Instituição de Ensino Superior na região, trazendo impactos, no caso do PRP, que podem ser identificados como política pública vista a natureza do programa envolver as redes públicas diretamente e, as redes privadas, pois o licenciando/residente e os preceptores participantes do programa também atuam nessas redes, muitas vezes, de forma concomitante (Magalhães et al., 2018, p. 10).

Algumas pesquisas, como a desenvolvida por Pinheiro, Gaspar e Ribeiro (2018) também me ajudaram a começar a entender alguns termos vindos do PRP e como este acontece. O EQ também nos auxiliou neste aspecto e isto pode contribuir para o entendimento do contexto de realização do PRP e colaborar na compreensão dos fundamentos teóricos do programa. Por exemplo, na Residência Pedagógica os estudantes da Licenciatura devem estar com mais de $50 \%$ do curso já concluído; existe um Coordenador Institucional (docente da Instituição de Ensino Superior - IES, responsável pelo projeto institucional de Residência Pedagógica); um Docente Orientador (docente que orientará o estágio dos residentes); e por fim, um Preceptor (professor da educação básica) que é quem estará atuando mais próximo dos residentes dentro da escola (Pinheiro, Gaspar, \& Ribeiro, 2018).

A maior mudança ocorreu na retirada da temática sexualidade da pesquisa de Dissertação, uma vez que através do EQ observamos melhor quem era meu objeto de estudo, percebendo que focar na sexualidade delimitaria muito a pesquisa, ao invés de expandi-la. Estudar o programa como um todo, ao invés de apenas para uma temática, certamente, foi a maior contribuição do EQ.

Ao fim, percebemos que cada trabalho nos ajudou a organizar de maneira mais concreta na delimitação da proposta científica, assim como no que se trata ao Referencial Teórico quanto ao Percurso Metodológico, além de já me ajudar a entender o que é o PRP. O Estado da Questão é algo um pouco mais complexo que uma simples Revisão Bibliográfica, e 
foi importante para que eu entendesse melhor o que mais existe na Literatura em termos de pesquisas similares a que se pretende executar para entender o PRP e a sua importância para a formação inicial dos futuros professores de Biologia.

Com esta pesquisa, fizemos um panorama na vertente Residência e as contribuições para os futuros professores. Porém, torna-se necessário mais trabalhos neste viés para que se entenda de maneira mais sólida tais contribuições para a escola e demais pessoas que são atingidas pelo programa. Muitos são os trabalhos que trazem o termo residência, mas em sua minoria estão relacionados com a Residência Pedagógica na educação, sendo em maior volume os relacionados à área da saúde, visto que também, de longo prazo se tem a residência na área da saúde, e só recentemente o programa foi inserido no meio educacional.

\section{Referências}

Abreu, A. R. L. (2017). Educação sexual e a formação de professores: uma proposta para a formação inicial dos licenciandos em ciências naturais (FUP) (Dissertação Mestrado). Programa de Pós-Graduação Stricto Sensu em Ensino de Ciências, Universidade de Brasília, Brasília, Distrito Federal, Brasil.

Barbedo, I. D. (2018). Programa Residência Pedagógica - UNIFESP: um estudo da inserção profissional à docência (Dissertação Mestrado). Programa de Pós-Graduação Stricto Sensu em Educação: Psicologia da Educação, Pontifica Universidade Católica de São Paulo, São Paulo, Brasil.

Brasil. (2014). Lei $n^{o}$ 13.005/2014. Estabelece o Plano Nacional de Educação (PNE) (20142024). Ministério da Educação. Recuperado: http://www.planalto.gov.br/ccivil_03/_ato20112014/2014/lei/113005.htm

Conceição, C. P. F. (2018). A inserção profissional do egresso do Programa Residência Pedagógica da Universidade Federal de São Paulo (UNIFESP) (Dissertação Mestrado). Programa de Pós-Graduação Stricto Sensu em Educação: Psicologia da Educação, Pontifica Universidade Católica de São Paulo, São Paulo, Brasil.

Costa, E. A. S., Rower, J. E., Colares, R. P., Silva, G. C., Peixoto, C. M. M., \& Silva, A. P. R. N. (2018 dezembro). O Programa Residência Pedagógica como encontro entre a formação 
inicial e contínua de professores. Anais do Encontro Nacional das Licenciaturas (ENALIC), Fortaleza, CE, 2018, 5.

Craveiro, T. S. U., Ferreira, A. F., Ozório, F. J. G. D., Noronha, G. N., \& Gomes, A. L. M. O. (2018 dezembro). O legado do Programa Institucional de Bolsa de Iniciação à Docência (PIBID) na escola alvorada: as expectativas frente às ações do Programa Residência Pedagógica (RP). Anais do Encontro Nacional das Licenciaturas (ENALIC), Fortaleza, CE, 2018,5 .

Cunha, R. S., Santos, M. R. S., Dittrich, J., Vicentini, M., Stavis, L. D. S. O., \& Marques, C. C. G. (2016). Formação inicial docente e suas relações dentro do âmbito escolar. Ciência \& Educação, 22(3), 585-596.

Gatti, B. A. (2010). Formação de professores no Brasil: características e problemas. Educação \& Sociedade, 31(113), 1355-1379.

Gatti, B., \& Nunes, M. M. R. (2009). Formação de professores para o ensino fundamental: estudo de currículos das licenciaturas em pedagogia, língua portuguesa, matemática e ciências biológicas. (v. 29). São Paulo, SP: Fundação Carlos Chagas.

Gil, A. C. (2008). Métodos e técnicas de pesquisa social. 6. ed. Ediitora Atlas SA.

Gonçalves, R. C., Marques, A. C. L., Carvalho, S. A. C, Gregório, E. S., D’Orazio, W. P. S., Sousa, K. F. G., Sousa, T. P., Marcelo, V. G., Caetano, R. V. O., Silva Júnior, A. D., Silva, G. J. A., Oliveira, J. F., Farias, L. G. M., Silva, A. P., Gontijo, O. J. S., Resende, P. S., Alves, M. A. S. B., \& Malafaia G. (2014). Relatando e refletindo sobre as experiências do PIBID biologia (IF Goiano-Câmpus Urutaí) no período de 2011 a 2013. HOLOS, 6, 267-279.

Guerta, R. S., \& Camargo, C. C. D. (2015). Comunidade de aprendizagem da docência em estágio curricular obrigatório: aprendizagens evidenciadas pelos licenciandos. Ciência \& Educação (Bauru), 21(3), 605-621. 
Lima, G. R., \& Ferreira, M. A. S. (2018). A formação docente e o PIBID-subprojeto de Biologia do IFRN/Macau: uma interlocução entre a formação inicial e continuada. HOLOS, 2 , 318-332.

Lira, M. R., Filho, J. J. S., Ferreira, U. L., \& Duarte, V. M. B. (2018 dezembro). Mobilizações do Programa Residência Pedagógica na Universidade de Pernambuco campus Mata Norte. Anais do Encontro Nacional das Licenciaturas (ENALIC), Fortaleza, CE, 2018, 5.

Lopes, K. A. R, Joaquim, W. M., \& Souza, A. A. M. (2018 dezembro). A multidisciplinaridade no PIBID e no PRP: novo desafio na formação docente. Anais do Encontro Nacional das Licenciaturas (ENALIC), Fortaleza, CE, 2018, 5.

Maciel, A. S., \& Rosa, R. T. D. D. (2016). Estágio de docência em biologia: relatos de experiências e constituição de identidades docentes. Revista Eventos Pedagógicos. Mato Grosso, 7(2), p. 680-704.

Magalhães, E. M. M. M., Costa, A. V. F., Coelho, S. R., \& Duarte, I. M. B. N. (2018 dezembro). Residência pedagógica e seus impactos nas escolas-campo da educação básia e nas licenciaturas. Anais do Encontro Nacional das Licenciaturas (ENALIC), Fortaleza, CE, $2018,5$.

Martines, E. A. L. M., \& Rossarolla, J. N. (2018). Sexo e sexualidade: tabu, polêmica ou conceitos polissêmicos? Reflexões sobre/para a formação de educadores. Revista Exitus, 8(2), 273-299.

Morais, J. K. C., \& Ferreira, M. A. D. S. (2014). Profissionalização docente: construindo saberes a partir da prática no PIBID. HOLOS, 5, 112-120.

Moura, F. N. M., \& Leite, R. C. M. (2020). A educação alimentar e nutricional em questão: desdobramentos na formação inicial de professores pedagogos. Research, Society and Development, 9(2), 109922141. 
Moura, F. N. S., \& Leite, R. C. M. (2019). O conservadorismo e a formação cidadã: a abordagem da Sexualidade no Ensino Fundamental diante do discurso em documentos oficiais. Educação, Ciência e Cultura, 24(3), 61-77.

Nóbrega-Therrien, S. M., \& Therrien, J. (2004). Trabalhos científicos e o estado da questão: reflexões teórico-metodológicas. Estudos em avaliação educacional, 15(30), 5-16.

Oliveira, L. M. (2018). Sexualidade: uma proposta metodológica para formação inicial de professores de ciências naturais (Dissertação Mestrado). Programa de Pós-Graduação Stricto Sensu em Ensino de Ciências, Universidade Federal de Brasília, Brasília, Distrito Federal, Brasil.

Oliveira, S. G. M. (2016). Formação inicial docente para a educação sexual: revelando realidades de licenciaturas em Ciências biológicas (Dissertação Mestrado). Programa de PósGraduação Stricto Sensu em Educação para a Ciência, Universidade Estadual Paulista, Bauru, São Paulo, Brasil.

Paniago, R. N., Sarmento, T., \& Rocha, S. A. (2018). O PIBID e a inserção à docência: experiências, possibilidades e dilemas. Educação em revista, 34, 1-31.

Pinheiro, F. M. R., Gaspar, M. L. R., \& Ribeiro, E. A. (2018 dezembro). Modelos inovadores no campo da formação docente inicial: um estudo analítico da implementação do PIBID e da Residência Pedagógica no IFTM. Anais do Encontro Nacional das Licenciaturas (ENALIC), Fortaleza, CE, 2018, 5.

Poladian, M. L. P. (2014). Estudo sobre o Programa de Residência Pedagógica na UNIFESP: uma aproximação entre Universidade e Escola na formação de professores (Dissertação Mestrado). Programa de Pós-Graduação Stricto Sensu em Educação: Psicologia da Educação, Pontífica Universidade Católica de São Paulo, São Paulo, Brasil.

Ribeiro, L. S. (2018). A educação científica diante dos currículos prescritos para os anos finais do ensino fundamental da educação pública de Fortaleza-CE (Dissertação Mestrado). Programa de Pós-Graduação Stricto Sensu em Educação Brasileira, Universidade Federal do Ceará, Fortaleza, Ceará, Brasil. 
Rosa, A. N., \& Goi, M. E. J. (2020). A utilização de textos de divulgação científica no ensino de Química. Research, Society and Development, 9(6), 123963480.

Santos, K. M. C. A., Santos, M. E. R., \& Alves, R. B. T. (2018 dezembro). Formação de professores na articulação escola/universidade: intenção e resultado parcial do programa de Residência Pedagógica na UFT. Anais do Encontro Nacional das Licenciaturas (ENALIC), Fortaleza, CE, 2018, 5.

Santos, M. C. G. (2016). As contribuições do currículo da formação para a prática pedagógica docente com gênero e sexualidade na educação básica (Tese Doutorado). Programa de Pós-Graduação Stricto Sensu em Educação, Universidade Federal de Pernambuco, Recife, Pernambuco, Brasil.

Silva, M. V. M., Dantas, L. K. S., \& Viana, F. R. (2020). Visibilidades no contexto surdo dentro do Programa de Residência Pedagógica. Research, Society and Development, 9(1), e166911771.

Vasconcelos, M. N. M. (2018). Relações de gênero, interseccionalidades e formação docente (Dissertação Mestrado). Programa de Pós-Graduação Stricto Sensu em Educação: formação de professores, Pontifica Universidade Católica de São Paulo, São Paulo, Brasil.

\title{
Porcentagem de contribuição de cada autor no manuscrito
}

\author{
Thaís Borges Moreira - 40\% \\ Raquel Crosara Maia Leite - 30\% \\ Francisco Nunes de Sousa Moura - 30\%
}

